\title{
Pengujian Mutu Papan Partikel dari Serbuk Gergaji yang Diisi Silika Gel Hasil Pemurnian Abu Sekam Padi
}

\author{
LangJagat 1), Mariana B. Malino 2) \\ 1) Politeknik Sambas \\ 2)Jurusan Fisika FMIPA Universitas Tanjungpura Pontianak \\ e-mail: Mariana.malino9@gmail.com
}

\begin{abstract}
Abstrak
Penelitian ini memanfaatkan silika dalam bentuk gel dari hasil pemurnian abu sekam sebagai adsorber air pada papan partikel dengan komposisi silika gel di dalam campuran $0 \%, 5 \%, 10 \%$ dan 15\%. Karakterisasi yang dilakukan meliputi meliputi pengujian: kerapatan, kadar air, pengembangan tebal, modulus patah, MOR dan keteguhan rekat internal,IB. Berdasarkan hasil pengujian papan partikel maka disimpulkan bahwa kadar silika optimum yang diperoleh dari penelitian adalah sebesar $5 \%$ dan berdasarkan analisis ekstrapolasi nilai hasil pengujian komposisi silika gel yang sebaiknya ditambahkan adalah $4,13 \%$.
\end{abstract}

Kata kunci: silika gel, sekam padi, papan partikel, uji mekanis, kadar air.

\section{Pendahuluan}

Abu sekam padi memiliki kandungan silika $\left(\mathrm{SiO}_{2}\right)$ hingga $97.30 \%$ dan ekstraksi silika dari abu sekam padi dapat dibuat dalam bentuk gel (Harsono, 2002; Malino, 2001) untuk dimanfaatkan sebagai bahan adsorber air (Santoso, 1991). Sifat silika gel sebagai bahan adsorber, dalam penelitian ini, dimanfaatkan sebagai penyerap air pada papan partikel karena kayu sebagai bahan dasar pembuatan papan partikel merupakan zat higroskopis, artinya mempunyai afinitas yang tinggi terhadap air, baik dalam bentuk uap maupun cairan. Hal tersebut disebabkan karena kayu memiliki kandungan selulosa yang tinggi yaitu sampai $40-50 \%$ sehingga memungkinkan terjadinya ikatan hidrogen antara gugus $\mathrm{OH}$ pada selulosa dengan air (Clausen, 2000; Febrianto, et al, 2003).

Pengujian mutu produk papan partikel yang dihasilkan, dilakukan sesuai standar uji JIS A 5908-94. Uji yang dilakukan berupa pengujian terhadap kerapatan, kadar air, pengembangan tebal, modulus patah (modulus of rapture, MOR) dan daya rekat internal (internal bonding, IB) (Sutigno,2002; Santoso, 1991; Vlack, 1994):

$\rho=\frac{m}{v}$

dengan: $\rho$ =kerapatan $\quad\left(\mathrm{g} / \mathrm{cm}^{3}\right), \quad \mathrm{m} \quad$ =massa sampel $(\mathrm{g}), \mathrm{V}=$ volume sampel $\left(\mathrm{cm}^{3}\right)$.

Kadar air dan pengembangan tebal ditentukan berdasarkan (Johnstone, et al, 1961).
Nilai MOR yang menyatakan ukuran kekuatan bahan dihitung menggunakan persamaan (Timoshenko, 1951):

$$
M O R=\frac{3 \cdot P l}{2 b h^{3}}
$$

dengan $:$ MOR $=$ modulus patah $\left(\mathrm{kg} / \mathrm{cm}^{2}\right), \mathrm{P}=$ Beban sampai patah $(\mathrm{kg}), \mathrm{l}=$ =Jarak sanggah $(\mathrm{cm})$, $\mathrm{b}=$ Lebar sampel $(\mathrm{cm}), \mathrm{h}=$ tebal sampel $(\mathrm{cm})$.

Nilai keteguhan rekat internal ditentukan berdasarkan hubungan[10].

$I B=\frac{P}{A x B}$

dengan : IB $=$ Keteguhan Rekat Internal $\left(\mathrm{Kg} / \mathrm{cm}^{2}\right), \mathrm{P}=$ Beban Maksimum $(\mathrm{Kg}), \mathrm{A}=$ Panjang $(\mathrm{cm}), \mathrm{B}=\operatorname{Lebar}(\mathrm{cm})$.

\section{Metode Penelitian}

Peralatan yang digunakan adalah neraca digital, ayakan ukuran 10 mesh dan 8 mesh, tanur, oven, cetakan papan partikel, mesin hot press, alat uji MOR dan alat uji keteguhan rekat. Bahan yang digunakan adalah serbuk gergaji, sekam padi, akuades, emulsi parafin (wax emulsion), asam klorida ( $\mathrm{HCl}) 37 \%$, asam sulfat $\left(\mathrm{H}_{2} \mathrm{SO}_{4}\right) 1 \mathrm{M}$, natrium hidroksida $(\mathrm{NaOH}) 5 \mathrm{M}$, kertas lakmus dan urea formaldehida 95, UF 95. Silika gel disintesis dengan mengacu pada (Harsono, 2002; Malino, 2001). Serbuk gergaji yang telah lolos ayakan 10 mesh untuk core dan 8 mesh untuk face/ back, dikeringkan dalam oven pada $100^{\circ} \mathrm{C}$ sampai mencapai kadar air tidak lebih dari $\pm 5 \%$. Konsentrasi UF dalam 
campuran adalah $12 \%$ dari bobot kering papan partikel. Papan partikel tiga lapis dengan perbandingan core dan face/back masing masing $50 \%$ dan target kerapatan $0,70 \mathrm{gr} / \mathrm{cm}^{3}$, dibuat dengan perbandingan serbuk gergaji : perekat : emulsi : berturut turut adalah 100 : 12 : 0,1. Konsentrasi silika gel dibandingkan terhadap bobot kering serbuk gergaji adalah $0 \%$ $\left(A_{1}\right), \quad 5 \% \quad\left(A_{2}\right), \quad 10 \% \quad\left(A_{3}\right)$ dan $15 \% \quad\left(A_{4}\right)$. Campuran dicetak dengan ukuran $30 \mathrm{~cm}$ x $30 \mathrm{x}$ $1 \mathrm{~cm}$ dan dikempa panas selama 5 menit pada $180{ }^{\circ} \mathrm{C}$ dengan tekanan $30 \mathrm{~kg} / \mathrm{cm}^{2}$. Pola pemotongan lembaran papan partikel mengacu pada sistem JIS 5908 - 1994. Papan partikel dikondisikan pada temperatur kamar selama satu minggu sebelum diuji.

\section{Hasil dan Pembahasan}

Berdasarkan hasil pengujian dalam Gambar 1, nilai kerapatan rerata tertinggi terdapat pada sampel $\mathrm{A}_{3}$ dan terendah adalah sampel A4. Standar JIS A 5908-94 mensyaratkan kerapatan rata-rata sampel papan partikel adalah 0,4-0,9 gr/ $\mathrm{cm}^{3}$. Gambar 1 menunjukkan nilai kerapatan papan partikel tidak linear terhadap konsentrasi silika gel.

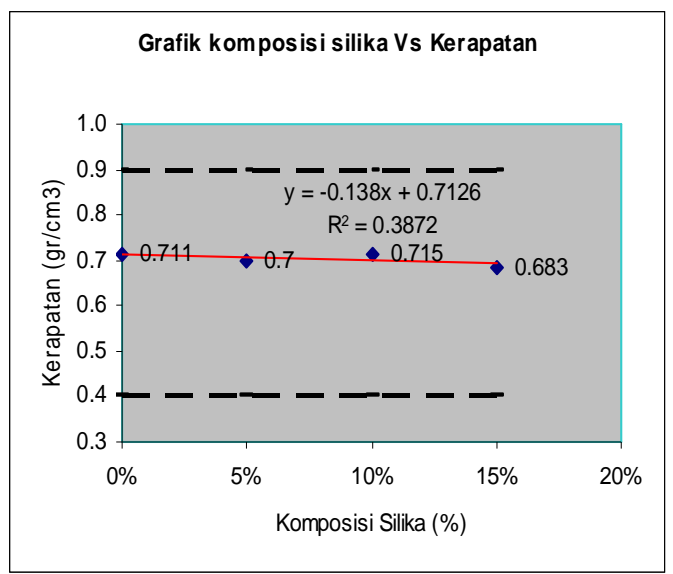

Gambar 1 Grafik kerapatan papan partikel

Keragaman limbah kayu yang digunakan sebagai bahan baku papan partikel diduga merupakan faktor yang menyebabkan adanya perbedaan kerapatan papan yang dihasilkan. Serbuk gergaji dari kayu lunak cenderung lebih mudah terpadatkan ketika diberikan tekanan kempa dibandingkan serpih yang berasal dari kayu keras.

Hasil pengujian kadar air rerata semua sampel memenuhi persyaratan standar JIS A 5908-94. Standar JIS A 5908-94 mensyaratkan kadar air papan partikel adalah 5 - $13 \%$. Gambar 2 menunjukkan bahwa kadar air semakin rendah dengan semakin tinggi komposisi silika yang ditambahkan. Fenomena tersebut berhubungan dengan fungsi dan sifat silika gel sebagai adsorber air. Pengikatan molekul air oleh silika gel dimungkinkan oleh struktur kimia silika gel yakni $\mathrm{SiO}_{2}$ dengan pembentukan ikatan molekular antara molekul $\mathrm{O}_{2}$ dari silika gel dengan gugus $\mathrm{OH}$ dari molekul air.

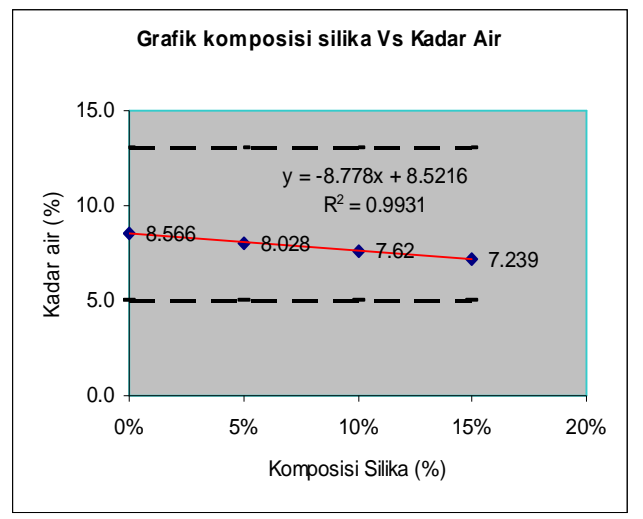

Gambar 2 Grafik komposisi silika gel dalam papan partikel terhadap kadar air

Standar pengujian JIS 5908-94 menetapkan nilai pengembangan tebal untuk papan partikel yang dihasilkan adalah $12 \%$. Berdasarkan hasil pengujian diketahui bahwa pengembangan rerata papan partikel yang dihasilkan setelah perendaman 2 jam adalah $2,828 \%-7,087 \%$ sedangkan pengembangan tebal rerata setelah dilakukan perendaman 24 jam adalah 6,202 \% - 9,001 \%. Grafik dalam Gambar 3 menunjukkan bahwa penambahan komposisi silika menyebabkan peningkatan pengembangan tebal papan partikel.

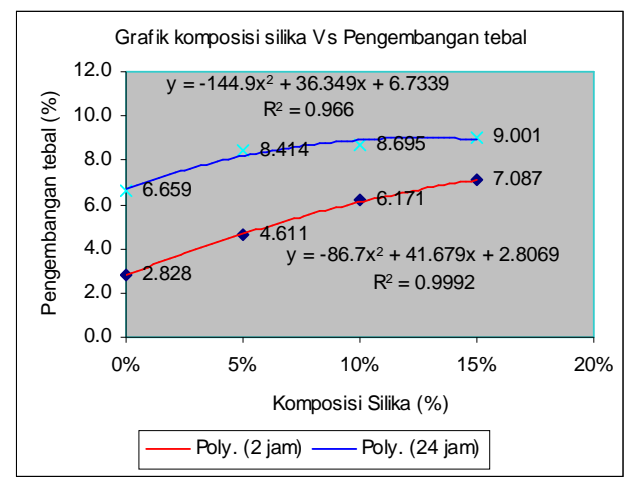

Gambar 3 Grafik komposisi silika gel terhadap pengembangan tebal papan partikel.

Berdasarkan hasil pengujian MOR dalam Gambar 4, nampak bahwa nilai MOR menurun seiring penambahan komposisi silika dan yang memenuhi Standar JIS 5908-04 untuk MOR papan partikel yakni minimal $82 \mathrm{~kg} / \mathrm{cm}^{3}$ adalah sampel yang tidak mengandung silika gel. 


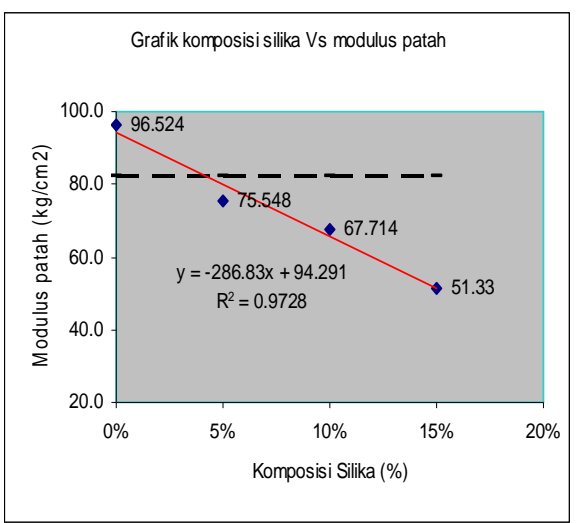

Gambar 4 Grafik komposisi silika gel dalam papan partikel terhadap nilai MOR

Silika gel merupakan molekul dengan struktur heksagonal tumpukan padat (heksagonal closed packed) yang membuat formasi cincin dengan enam atom silikon sehingga membentuk jaringan tiga dimensi yang kaku dan keras. Akibatnya, penambahan silika gel pada papan partikel akan menyebabkan elastisitas papan partikel berkurang dan selanjutnya menyebabkan papan partikel menjadi getas.

Hasil pengujian IB papan partikel menunjukkan bahwa IB meningkat seiring dengan penambahan komposisi silika. Hal tersebut dikarenakan semakin banyak jumlah silika yang ditambahkan mengakibatkan rendahnya kadar air pada papan partikel karena terserap oleh silika, sehingga daya rekat semakin tinggi. JIS mensyaratkan nilai minimum untuk IB adalah $3,1 \mathrm{~kg} / \mathrm{cm}^{2}$ jadi semua papan partikel yang dihasilkan memenuhi standar JIS A 5908-94.

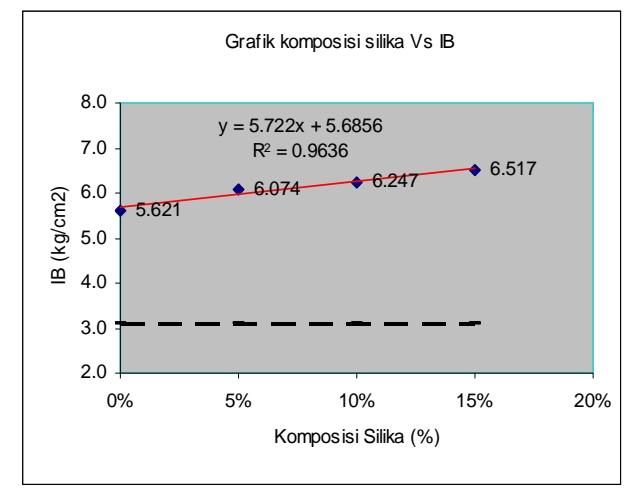

Gambar 5 Grafik komposisi silika gel dalam papan partikel terhadap nilai IB

Berdasarkan karakterisasi terhadap sampel yang telah dibuat, disimpulkan bahwa komposisi silika optimum dalam papan partikel adalah 5\% $\left(\mathrm{A}_{1}\right)$ dan berdasarkan hasil ekstrapolasi nilai-nilai hasil pengujian diperoleh komposisi silika yang sebaiknya ditambahkan adalah sebesar 4,13\%, seperti ditunjukkan dalam Gambar 6.

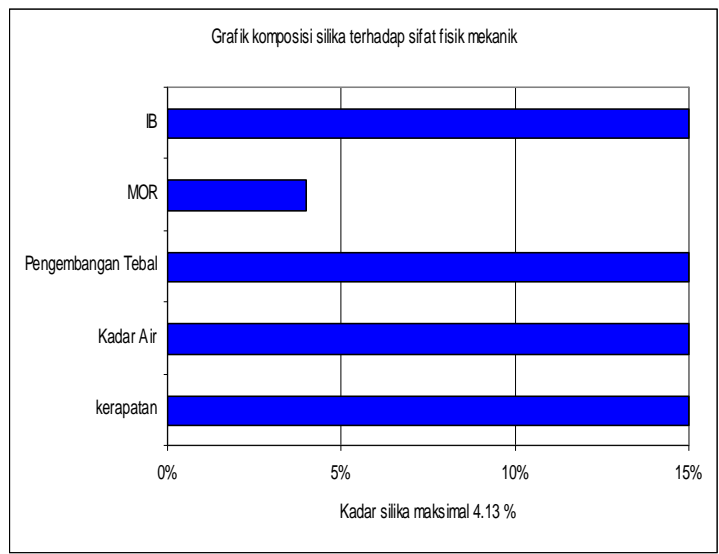

Gambar 6 Grafik penentuan kadar silika optimum

\section{Kesimpulan}

Papan partikel yang dihasilkan dapat dikelompokkan ke dalam papan partikel berkerapatan sedang $\left(0,638-0.715 \mathrm{~g} / \mathrm{cm}^{3}\right.$.

Komposisi silika optimum adalah 5\% $\left(\mathrm{A}_{1}\right)$ dengan nilai kerapatan papan partikel 0,7 $\mathrm{g} / \mathrm{cm}^{3}$, ), kadar air 8,082\%, pengembangan tebal $8,414 \%$ dan $6,111 \%$, MOR $75,548 \mathrm{~kg} / \mathrm{cm}^{2}$ danIB $6,074 \mathrm{~kg} / \mathrm{cm}^{2}$ dan berdasarkan hasil ekstrapolasi nilai-nilai hasil pengujian diperoleh komposisi silika yang sebaiknya ditambahkan adalah sebesar $4,13 \%$

\section{Ucapan Terima Kasih}

Penulis menyampaikan ucapan terima kasih kepada pihak DIKTI yang telah mendanai penelitian ini melalui hibah Dosen Muda 2007.

\section{Daftar Pustaka}

Clausen,C.A., Kartal S.N., and Muehl, J, 2000, Properties of Particle Board Made from Recyled CCA-Treated Wood, SE-100 44, Stockhlom, Sweeden

Febrianto, F. M .Yoshioka and N. Shiraishi. Composite of Wood and Polyactic Acid V: Porperties of Wood in Relation to Fiber Pretreatment Technique and Processing Condition, Jurnal Teknologi Hasil Hutan,16. 1-9(2003)

Harsono, H., Pembuatan Silika Amorf dari Limbah Padi . Jurnal Ilmiah Dasar,3. 98103(2002)

Johnstone, J. Sidney and Margery J., 1961, Minerals for the Chemical and Apllied Industry, Second ed. John Wiley \& Sons Ltd. New York.

Malino, Mariana B., Penentuan Derajat Kristalinitas Silika Hasil Pemurnian Abu 
Sekam Padi dan Pembuatan Silika Gel, 2001, Skripsi, UNIBRAW, Malang

Massiwijaya, Y dan A. Gunawan, Optimasi Kadar Perekat dalam Pembuatan Papan Komposit dari Limbah Kayu dan Karton Gelombang. Jurnal Teknologi Hasil Hutan, 17. 7280(2004]Santoso, Budi, 1991, Konsep dan Prosedur Analisa Tanaman, FapertaUNIBRAW, Malang

Sutigno,P., 2002, Mutu Papan Partikel (http:// www.dephut.go.id)

Vlack, van Lawwrence. 1994. Ilmu dan Timoshenko,S., 1951, Theory of Elasticity, Second Edition, Mc.Graw-Hill Co. New York Teknologi Bahan. Penerbit Erlangga. 